\title{
An outbreak of Portuguese man-of-war (Physalia physalis - Linnaeus, 1758) envenoming in Southeastern Brazil
}

\author{
Vidal Haddad Junior ${ }^{[1]}$, Rossana Virga ${ }^{[2]}$, Adriano Bechara ${ }^{[3]}$, \\ Fábio Lang da Silveira ${ }^{[4]}$ and André Carrara Morandini ${ }^{[4]}$
}

[1]. Departamento de Dermatologia e Radioterapia, Faculdade de Medicina de Botucatu, Universidade Estadual Paulista, Botucatu, SP. [2]. Aquário do Guarujá, Prefeitura Municipal de Guarujá, Guarujá, SP. [3]. Secretaria da Saúde, Prefeitura Municipal de Praia Grande, Praia Grande, SP. [4]. Departamento de Zoologia, Instituto de Biociências, Universidade de São Paulo, São Paulo, SP.

\begin{abstract}
Introduction: Portuguese man-of-war, Physalia physalis (Linnaeus, 1758), are cnidarians capable of discharging intracellular organelles filled with venom, resulting in severe envenomation in humans. Methods: We report the clinical and therapeutic aspects of 331 accidents involving Portuguese man-of-war in an outbreak on the coast of the State of São Paulo, Brazil. Results: The clinical manifestations of envenomation were rare and mild and mostly local, systemic reactions; there was a low rate of late complications. Conclusions: The consequences of envenomation were of moderate severity, and first aid measures were effective in controlling the pain. Outbreaks of accidents involving Portuguese man-of-war occur periodically in the area without a clear explanation.
\end{abstract}

Keywords: Bites and Stings. Physalia physalis. Cnidaria venom.

The Portuguese man-of-war, Physalia physalis (Linnaeus, 1758), are cosmopolitan marine animals belonging to the phylum Cnidaria, class Hydrozoa. They are considered colonies of polyps, not true jellyfish, and are characterized by the presence of a floating bag (pneumatophore) and the absence of swimming structures ${ }^{1}$. Portuguese man-of-war usually bear multiple dactylozooids (in the shape of tentacles), which are capable of discharging thousands of intracellular organelles (cnidae) filled with venom that are mainly used to capture prey or in defense $\mathrm{e}^{2}$. The discharge of cnidae depends on mechanical and chemical stimuli and occurs at high pressure through a device, similar to a switchblade, capable of injecting microdrops of venom deep within the prey's or other predator's body3.

When there is contact between cnidarians and humans, severe envenoming can occur. The venom is composed of toxic substances with necrotic, neurotoxic (pain) and cardiotoxic effects $^{3}$. The local signs of envenomation include a few long (more than $20 \mathrm{~cm}$ ), linear erythematous and edematous plaques (imprints of the tentacles), blisters and skin necrosis ${ }^{4,5}$. The local symptoms include intense pain and a burning sensation. Severe cases of envenomation can have systemic manifestations, including vomiting, nausea, arterial hypotension, seizures, cardiac arrhythmias, respiratory failure ${ }^{6}$ and sometimes death ${ }^{7}$.

\footnotetext{
Address to: Dr. Vidal Haddad Junior. Depto. Dermatologia e Radioterapia/FMB/ UNESP. Caixa Postal 557, 18618-00 Botucatu, SP, Brasil.

Phone/Fax: 5514 3882-4922

e-mail: haddadjr@fmb.unesp.br

Received 22 January /2012

Accepted 1 June 2012
}

In Brazil, Portuguese man-of-war are common in the North and Northeast regions $\mathrm{s}^{4,5}$. In the State of Maranhão, there are hundreds of accidents involving Portuguese man-of-war in the surrounding areas of the capital of São Luis. To address this issue, a group has promoted educational efforts in the local population to raise awareness of this public health problem ${ }^{8}$. However, in the South and Southeast regions of Brazil, Portuguese man-of-war are rare, and envenoming cases are seldom reported ${ }^{4,5}$.

The treatment utilizes cold water compresses (recent studies demonstrate good pain control with the use of hot water compresses $)^{9}$ and vinegar baths to prevent additional discharge of nematocysts ${ }^{3,10}$.

The purpose of our work is to present a report of a large number of accidents involving Portuguese man-of-war in Southeastern Brazil and to discuss our treatment results using cold marine water compresses.

At the beginning of the 2008 austral summer, local newspapers reported thousands of envenoming events associated with Portuguese man-of-war (Figure 1) in an area that included three counties and approximately $100 \mathrm{~km}$ of the southern coastal State of São Paulo, Brazil. We were able to examine 331 patients observed over a period of four days (27 to 30 December, 2008). The patients were examined in two Emergency Care Centers of Praia Grande county $\left(23^{\circ} 49^{\prime} \mathrm{S} 46^{\circ} 02^{\prime} \mathrm{W}, 24^{\circ} 19^{\prime} \mathrm{S} 46^{\circ} 59^{\prime} \mathrm{W}\right)$, and their clinical records were registered according to the standard municipal protocols. The patients were treated following first aid care adopted in Brazil and previously reported and listed in the current medical literature ${ }^{4,5,11,12}$. The use of the images of the envenomation sites and data collection for medical 


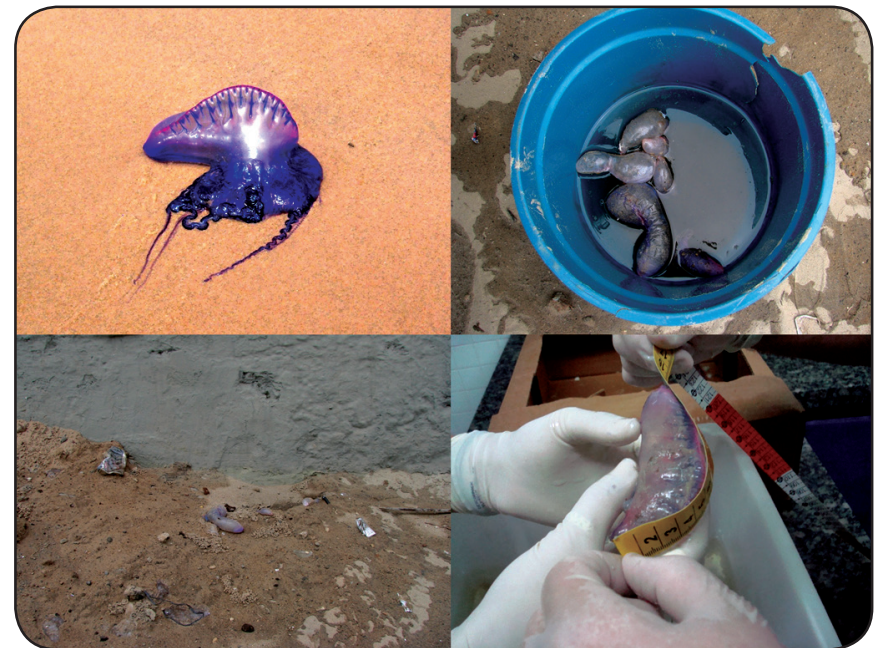

FIGURE 1 - Specimen of Portuguese man-of-war (Physalia physalis) found stranded on a beach at Praia Grande county (SE Brazil) on December 28, 2008. The solitary animal was $34 \mathrm{~cm}$ in total size. Photographs: Rosângela Maria Pires da Costa and Vidal Haddad Junior. Below, at right: measurement of the specimens found on the Praia Grande beach. Photographs: Rossana Virga.

purposes were authorized by patients after verbal and written consent according to an authorization model allowed by the Health Department of the Praia Grande Municipality. Patients' addresses were also registered, allowing further communications and followup for possible later signs and symptoms described in other studies involving cnidarians ${ }^{7}$. A questionnaire was sent to the victims two years after the accidents (January 2010), and the answers were recorded and added to the initial information about the outbreak.

Of the 331 patients observed and treated, $210(63.4 \%)$ were men and $121(36.5 \%)$ women. The ages of victims ranged from months to 60 years, with a peak between 10 and 19 years accounting for $144(43.5 \%)$ cases. Regarding the period of the accidents, $3(0.9 \%)$ occurred on December 272008,312 $(94.3 \%)$ on December 28, 4 (1.2\%) on December 29 and 12 (3.6\%) on December 30. Figure 2 shows the number of accidents in relation to the time of the day.

All patients had the same local physical signs: linear erythematous plaques of variable length (mean $18 \mathrm{~cm}$ ) that were intensely painful. The skin lesions presented a characteristic rosary-like pattern, following the banded or segmented tentacles and reflecting the battery of nematocysts (Figure 3).

Affected body parts were recorded. The upper limbs were the most compromised sites, with 126 (38\%) patients, and 54 $(16.3 \%)$ patients had lesions on their hands. The lower limbs had lesions in $90(27.1 \%)$ patients. The chest was compromised in $81(24.4 \%)$ patients, the abdomen in $24(7.2 \%)$ and the head in $9(2.7 \%)$. Some patients had lesions on more than one segment; $63(19 \%)$ patients had multiple segments affected, and $45(13.6 \%)$ had linear plaques on the chest and hands.

Cold sweats were the most common systemic manifestation in $54(16.3 \%)$ patients, followed by vomiting/nausea in $33(9.9 \%)$ patients and tachycardia in $24(7.2 \%)$ patients, whereas chest pain and arterial hypertension were each present in $3(0.9 \%)$ patients.

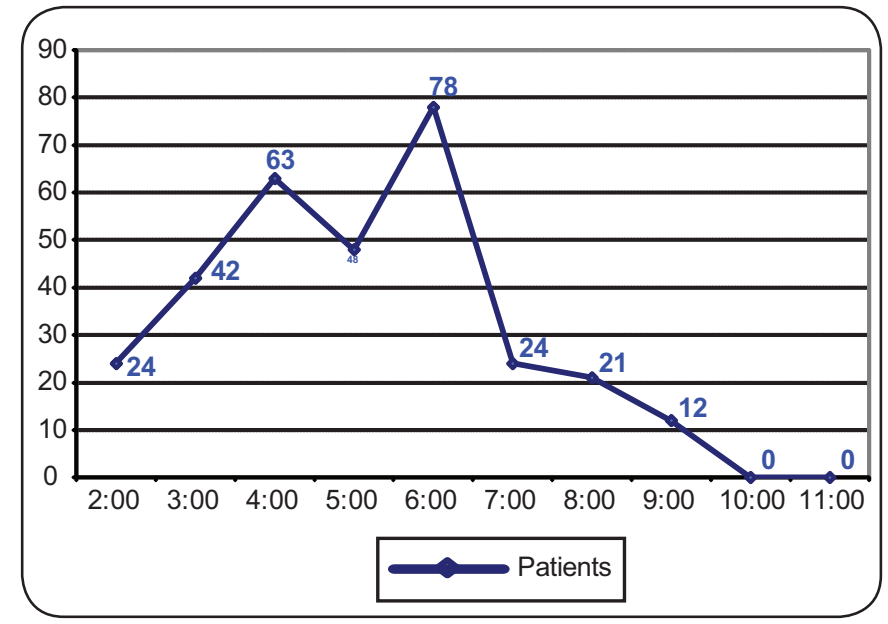

FIGURE 2 - Time of day that contact with Portuguese man-of-war occurred (data provided by patients). December 28, 2008 was considered the peak of the outbreak.

The treatment (first aid measures) used vinegar baths (acetic acid 4-8\%) and cold marine water compresses in $279(84.2 \%)$ patients. Of those affected, 49 (14.8\%) patients arrived at the Emergency Care Centers without pain and dismissed treatment, and $3(0.9 \%)$ patients refused any treatment.

Though they were not evaluated using a pain scale, all patients initially had severe pain. Of the 279 patients treated with cold marine water and vinegar, 247 (88.5\%) experienced significant reductions of pain within $3 \mathrm{~h}$, and 23 (8.2\%). Despite initial treatment, 16 children continued to have significant pain; in these last patients, we used intramuscular dipyrone as additional therapy, resulting in remission of pain. Trends in pain level were unknown in $9(3.2 \%)$ patients.

Questionnaires with stamped return envelopes were sent to all patients approximately two years after the outbreak. Questionnaires were completed and returned by 124 (37.4\%) patients. Late clinical symptoms (following the resolution of the initial manifestations of envenomation) were reported in 16 (12.9\%) patients; the local persistence of pigmentation was most common ( $8.8 \%$ of responses). Pruritus persisted for months in 3 $(2.4 \%)$ patients. Both local chronic pain and the persistence of linear plaques were observed in $1(0.8 \%)$ patient each.

Along beaches of the central part of the State of São Paulo coast, large aggregations of Physalia physalis have been observed over the last 16 years. During the study period, we monitored area and local newspapers and noted that aggregations of $P$. physalis occurred at irregular intervals (1994, 2002, 2008 and 2009). The sudden appearance of these animals was in the summer months (coinciding with school vacation). The species has an oceanic distribution, and its presence in coastal areas is considered unusual. Body morphology ${ }^{13,14}$, water currents and wind direction (Brazilian Navy data) may facilitate aggregation of $P$. physalis in coastal waters. In 1992, Pagès \& Gili also commented on discovering $P$. physalis colonies in the Benguela System after storms and strong winds ${ }^{15}$. The presence of specimens of differing sizes suggests that reproduction and development are not restricted to a certain period of the year. Our interpretation is that a combination of all mentioned factors (mainly winds) leads to the appearance and aggregation of 


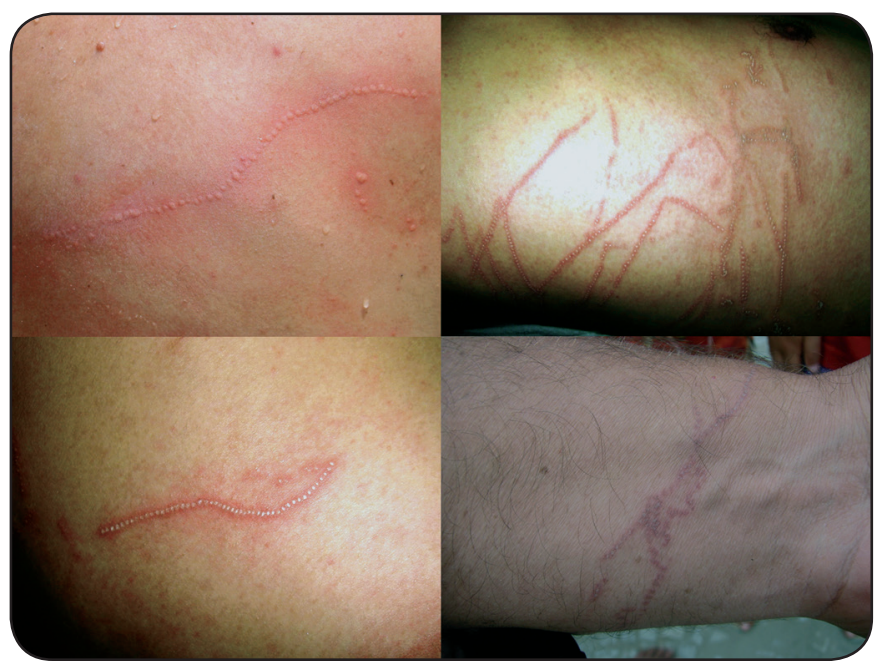

FIGURE 3 - Linear plaques brought about by contact with Portuguese man-ofwar. Note that the lesions present different stages. The urticaria-like pattern occurs in early lesions, and the frost aspect is associated with superficial skin necrosis caused by the venom. Top, at left: a sting after $2 \mathrm{~h}$ on the dorsum of a patient. Top, at right: a sting after $12 \mathrm{~h}$ on the lateral chest; note that the patient is lying down. Below, at left: a sting after $12 \mathrm{~h}$ on the dorsum. Below, at right: a sting after $24 \mathrm{~h}$ on the wrist. Photographs: Shirley Pacheco de Oliveira and Vidal Haddad Junior

Physalia in a short period of time and in a restricted area of the southeastern Brazilian coast.

In this outbreak, a large number of Physalia specimens were observed on the water and in the beaches over a four-day period, with a peak on December 282008 in the Praia Grande, Mongaguá, São Vicente and Guarujá municipalities (data from local newspapers). Fifty animals were collected, and tentacle lengths were measured (mean $42.45 \mathrm{~cm}$ ).

All patients presented the typical clinical manifestations of envenomation by Portuguese man-of-war, with patterns consisting of small numbers of long, linear plaques as previously described $^{4,5}$. Some plaques presented a frost aspect likely linked to superficial skin necrosis. The pain was constant, an important diagnostic characteristic of the accident, as the marks and pain are instantaneous. Together with the symptoms and the presence of numerous specimens of Portuguese man-of-war in the water and on the sand, we were able to confirm the identification of the stings.

A predominant number of accidents involved males (63.4\%). The most affected age group ranged from 10 to 19 years of age, which is compatible with the most active age group. When considering only December 28, with the highest number of envenomation accidents, the peak number of accidents occurred during late morning and early afternoon, when young people often go to the beaches.

The upper limbs were more commonly affected (38.1\%), with a high frequency of hand injuries (16.3\%). With the arrival of the greatest number of Portuguese man-of-war and beaches full of bathers, a single animal may have injured more than one bather. The swimmers tended to remain in shallow waters, which may account for the other body segments most affected (lower limbs and chest, $27.1 \%$ and $24.4 \%$, respectively). Many victims had involvement in more than one segment, mainly upper limbs, chest and hands.

Systemic phenomena were relatively rare: cold sweats were observed in $16.3 \%$ of patients but could have been linked to pain and stress. Three patients had tachycardia, and 3 had peaks of arterial hypertension. Both hypotension and hyperternsion can occur. No respiratory problems were reported. In general, the manifestations observed were not severe and were restricted to local signs and symptoms. It is worth noting this, as envenomation by Portuguese man-of-war is traditionally associated with major consequences, including death ${ }^{7,8}$.

Treatment was performed using cold seawater compresses and bathing envenomation sites with vinegar. The pain disappeared in $88.5 \%$ of the patients within three hours; if not treated, the painful process may last for up to $24 \mathrm{~h}^{5,6}$. In $8.2 \%$ of the cases treated, intramuscular dipyrone was needed to manage pain that persisted even with cold seawater compresses and vinegar. This additional procedure was able to provide pain relief. As hot water can also be used with good results for pain control $^{10}$, we think that extreme temperatures may be linked to the effects of hot and cold water over the course of the painful experience and may be related to the action of the venom.

Questionnaires to determine late manifestations were answered by $37.4 \%$ (124) of patients in this study. The frequency of late complications was low (12.9\%), and persistence of pigmentation occurred in $8.8 \%$ of the cases. One patient reported persistence of pain, and another reported the persistence of linear plaques for months after the initial contact.

Outbreaks of envenomation by Portuguese man-of-war are reported to occur in the studied region but still without a clear explanation. Summer months are the peak tourist season and are associated with a higher number of animals, more people on the beaches and more accidents occur inamong bathers; a high number of bathers are involved in accidents with marine animals during this season. In this report, more than 300 envenomation events were registered and related to the hydrozoan Physalia physalis. The stings were considered of mild severity, contrasting with the reported severe stings and even deaths in other parts of the world. Treatment of the local symptoms (cold sea water compress and vinegar baths) was the only procedure applied in most of cases. Systemic phenomena and later complications after the envenomations were rare and discrete.

\section{ACKNOWLEDGMENTS}

The authors are grateful to the Marinha do Brasil (Brazilian Navy) for providing water current and wind direction data.

\section{CONFLICT OF INTEREST}

The authors declare that there is no conflict of interest.

\section{FINANCIAL SUPPORT}

A previous version of this paper was presented by ACM at the $3^{\text {rd }}$ International Jellyfish Blooms Symposium in Mar del Plata, Argentina, funded by Conselho Nacional de Desenvolvimento Científico e Tecnológico (490348/2006-8 to Antonio C. Marques). ACM was partly supported by Fundação de Amparo à Pesquisa do Estado de São Paulo (2010/50174-7). 


\section{REFERENCES}

1. Pugh PR. Siphonophorae. In: Boltovskoy D, editor. South Atlantic Zooplankton. $1^{\text {st }}$ edition. Leiden: Backhuys; 1999. p. 467-511.

2. Fautin DG. Structural diversity, systematics, and evolution of cnidae. Toxicon 2009; 54:1054-1064.

3. Burnett JW. Medical aspects of jellyfish envenomation: pathogenesis, case reporting and therapy. Hydrobiologia 2001; 451:1-9.

4. Haddad-Jr V, Silveira FL, Cardoso JLC, Morandini AC. A report of 49 cases of cnidarian envenoming from southeastern Brazilian coastal waters. Toxicon 2002; 40:1445-1550.

5. Haddad-Jr V, Silveira FL, Migotto AE. Skin lesions in envenoming by cnidarians (Portuguese man-of-war and jellyfish): etiology and severity of accidents on the Brazilian coast. Rev Inst Med Trop Sao Paulo 2010; 52:47-50.

6. Burnett JW, Calton GJ, Burnett HW. Jellyfish envenomation syndromes. J Am Acad Dermatol 1986; 14:100-106.

7. Burnett JW, Gable WD. A fatal jellyfish envenomation by the Portuguese man-o'-war. Toxicon 1989; 27:823-824.
8. Nunes J. Projeto Physalia [Internet]. São Luís; Universidade Federal do Maranhão [cited in 2012 Jan 21]. Available from: http://projetophysalia. blogspot.com

9. Loten C, Stokes B, Warsley D, Seymour JE, Jiang S, Isbister GK. A randomized controlled trial of hot water $\left(45^{\circ} \mathrm{C}\right)$ immersion versus ice packs for pain relief in bluebottle stings. Med J Aust 2006; 4:329-333.

10. Burnett JW. Treatment of Atlantic cnidarian envenomations. Toxicon 2009 54: 1201-1205.

11. Haddad Jr V. Animais aquáticos potencialmente perigosos do Brasil: guia médico e biológico (Pottentially dangerous aquatic animals of Brazil: a medical and biologiocal guide). $1^{\text {st }}$ edition. São Paulo: Editora Roca; 2008.

12. Haddad Jr V. Animais aquáticos de importância médica. Rev Soc Bras Med Trop 2003; 36:591-597.

13. Woodcock AH. A theory of surface water motion deduced from the windinduced motion in Physalia. J Mar Res 1944; 5:196-205.

14. Bardi J, Marques AC. Taxonomic redescription of the Portuguese man-ofwar, Physalia physalis (Cnidaria, Hydrozoa, Siphonophorae, Cystonectae) from Brazil. Iheringia, Série Zoologia 2007; 97:425-433.

15. Pagès F, Gili JM. Siphonophores (Cnidaria, Hydrozoa) of the Benguela Current (southeastern Atlantic). Sci Mar 1992; 56:65-112. 